\title{
Preparation and Expansion Properties Analysis of C60 Expansive Self-compacting Concrete
}

\author{
JIA Li-li ${ }^{1}$ a $^{*}$, WU Jing ${ }^{2}$, ZHU Jian-long ${ }^{1}$ and YANG Long ${ }^{1}$ \\ ${ }^{1}$ China Construction Ready Mixed Concrete CO. LTD, Wuhan, 430074, China \\ ${ }^{2}$ Wuhan Textile University, Wuhan, 430074, China \\ jiali608927@126.com ${ }^{1}$
}

\begin{abstract}
Concrete Design of concrete filled steel tube should not only meet the requirements of self-compacting, but also need suitable expansion properties. On the basis of working performance requirement, study impact of expansive agent on concrete working performance, strength and expansion properties, preparation of $\mathrm{C} 60$ concrete filled steel to meet the self-compacting and expansion properties. Expander should not be too much, otherwise working performance and strength will be affected. Meanwhile study the correlation between restrained expansion and free expansion of expansive concrete, and analyze the mechanism of expansive concrete.
\end{abstract}

\section{Introduction}

Concrete filled steel tube has been increasingly widely used in bridge engineering and high-rise buildings, for its high bearing capacity, good seismic performance, save steel and construction simplicity and other advantages. However, the series of problems in concrete material itself, concrete filled steel tube in service facing changes in ambient temperature, creep and bearing axial pressure and other issues, make concrete and steel wall debonding and cavity is formed, and make difficult to take full advantage of composite design of concrete and steel tube. Meanwhile, because of the complex structure of giant concrete filled steel tubular column, it's difficult to vibrating and compacting during the concrete construction, which can not only affect the concrete strength, but also have security risks ${ }^{[1-2]}$.

Concrete Design of concrete filled steel tube should not only meet the requirements of self-compacting, but also need suitable expansion properties. The key of structural properties of concrete filled steel tube is interaction and collaboration between the steel tube and core concrete, thus making concrete filled steel tube with a series of excellent mechanical properties ${ }^{[3-4]}$. In experiment, on the basis of working performance requirement, study impact of expansive agent on concrete performance, strength and expansion properties, to prepare C60 concrete filled steel meeting the self-compacting and expansion properties. Study the correlation between restrained expansion ratio and free expansion rate of concrete, to analyze

* Corresponding author: jiali608927@126.com 
the expansion properties and forces of expansive concrete in the condition of unidirectional limited.

\section{Raw Materials}

The P.O52.5 cement is produced by Yadong cement plant. The basic properties are shown in Table 1. I fly ash is produced in Hubei with the average particle size of $D_{50}$ is $12 \mu \mathrm{m}$, fly ash microsphere is produced in Tianjin with the average particle size of $D_{50}$ is $1 \mu \mathrm{m}$. Main physical properties indicators are shown in Table 2.

TABLE 1 THE BASIC PROPERTIES OF CEMENT

\begin{tabular}{|c|c|c|c|c|c|c|c|c|}
\hline \multirow{2}{*}{$\begin{array}{c}\text { Standard } \\
\text { consistenc } \\
\text { y water[g] }\end{array}$} & \multicolumn{3}{|c|}{ Flexural strength[MPa] } & \multicolumn{2}{|c|}{ Compressive strength[MPa] } & \multirow{2}{*}{\multicolumn{2}{|c|}{$\begin{array}{c}\text { Density }\left[\mathrm{g} \cdot \mathrm{cm}^{-3}\right. \\
]\end{array}$}} & \multirow[t]{2}{*}{ Stability } \\
\hline & $3 \mathrm{~d}$ & $28 \mathrm{~d}$ & & $3 d$ & $28 \mathrm{~d}$ & & & \\
\hline 135 & 6.8 & 11.4 & & 33.6 & 60.5 & & & $\begin{array}{c}\text { Qualifie } \\
\text { d }\end{array}$ \\
\hline \multicolumn{9}{|c|}{ TABLE 2 PHYSICAL PROPERTIES OF CEMENT, FLY ASH AND S95 SLAG } \\
\hline \multicolumn{2}{|c|}{ Raw materials } & $\begin{array}{l}\text { Density } \\
/ \mathrm{g} \cdot \mathrm{cm}^{-3}\end{array}$ & $\begin{array}{r}\text { The } \\
\mathrm{s} \\
\text { area }\end{array}$ & $\begin{array}{l}\text { specific } \\
\text { urface } \\
\mathrm{a} / \mathrm{m}^{2} \cdot \mathrm{kg}^{-1}\end{array}$ & $\begin{array}{l}\text { Water } \\
\text { demand } \\
\text { ratio/\% }\end{array}$ & \multicolumn{3}{|c|}{$\begin{array}{l}\text { Compressive } \\
\text { strength ratio of } \\
28 \mathrm{~d} / \%\end{array}$} \\
\hline \multicolumn{2}{|c|}{ cement } & 3.20 & & 350 & 100 & 60.5 & \multicolumn{2}{|c|}{100.0} \\
\hline \multicolumn{2}{|c|}{ I fly ash } & 2.20 & & 330 & 110 & 42.0 & \multicolumn{2}{|c|}{68.3} \\
\hline \multicolumn{2}{|c|}{ fly ash } & 2.73 & & 950 & 95 & 50.3 & \multicolumn{2}{|c|}{81.8} \\
\hline \multicolumn{2}{|c|}{ S95 slag } & 2.80 & & 455 & 105 & 51.0 & \multicolumn{2}{|c|}{98.1} \\
\hline
\end{tabular}

Select high efficiency composite expanders BM-HCSA with the mortar restrained expansion ratio is $0.15 \%$ for $7 \mathrm{~d}$ water curing, and mortar restrained expansion ratio of $0.20 \%$ for $21 \mathrm{~d}$ standard curing. The phase composition of expanders is test by XRD analysis, mainly consist of $\mathrm{CaO}$, sulphoaluminate and $\mathrm{MgO}$.

High range polycarboxylate water reducer (PC) is used, with the solid content is $20 \%$, water reduction rate is $25 \%$.

\section{Testing Method}

Concrete Restrained Expansion Ratio Test. Concrete restrained expansion ratio is an important indicator of its expansion properties. It's testing process reference to GB50119-2003 "Code for utility technical of concrete admixture". Dimensions of specimens are $100 \mathrm{~mm} \times 100 \mathrm{~mm} \times 300 \mathrm{~mm}$ (Test equipment as shown in Figure 1), and the used unidirectional restraints steel skeleton is specified in GB 1499.2.

Concrete Free Expansion Rate Test. Making the non-contact measurement of concrete deformation of 1d reference to GB/ T50082-2009 "Standard for test methods of long-term performance and durability of ordinary concrete". Dimensions of specimens are $100 \mathrm{~mm} \times 100 \mathrm{~mm} \times 515 \mathrm{~mm}$. After $1 \mathrm{~d}$ demold, adopt the positioning device measuring of concrete expansion and contraction deformation (as shown in Figure 2),.which is separated from concrete specimen, and not constrained expansion behavior of the specimen. 


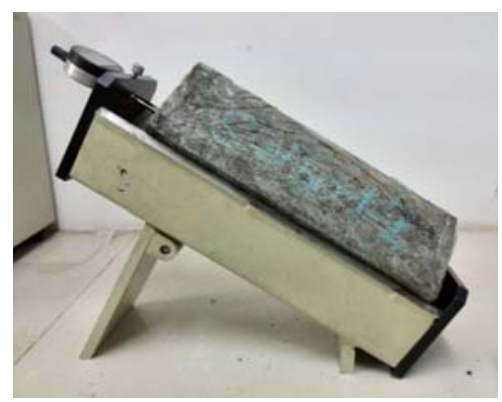

Fig.1 Test equipment of concrete restrained expansion

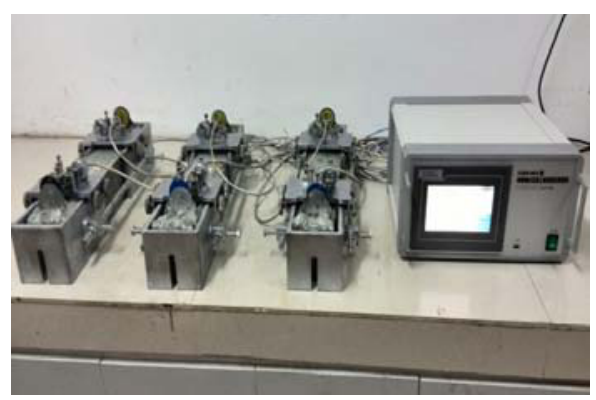

Fig.2 Non-contact test with positioning device

Concrete Working Performance Test. The test is performed according to GB/T 50080-2002 "Performance Test Method for Ordinary Mixed Concrete". Concrete cohesiveness is tested by a simple viscometer (determine the emptying time of concrete with an inverted slump cone). The slump method characterized workability of concrete. Self-compacting effects are tested by a U-box method described in JGJ/T283-2012“Technical Specification for Application of Self-compacting Concrete”. Its self-compacting ability is achieved by measuring the height difference between the two chambers, as shown in Figure 3.

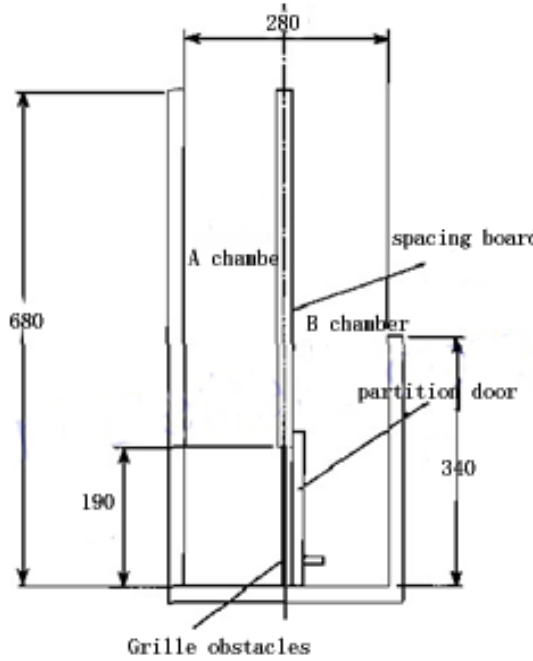

(b) U-Box of B type

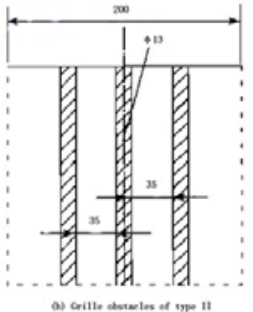

Fig.3 Schematic of U-Box for self-compacting performance tests

\section{Testing Results and Analysis}

Working Performance and Strength of Concrete. The test is performed to prepare C60 self-compacting concrete fist, according to JGJ/T283-2012“Technical Specification for Application of Self-compacting Concrete", with the volume fraction of coarse aggregate is 0.34 , and volume fraction of sand is 0.42 , and by calculation and practical experience, to determine the sand rate of 0.44 , water-cement ratio of 0.27 . On the basis of working 
performance requirement, study impact of expansive agent on concrete working performance, strength and expansion properties, the mix ratio is shown in Table 3, dosage of expansive agent is $4 \% \sim 12 \%$.

TABLE 3 MIX RATIO OF C60 EXPANSIVE SELF-COMPACTING CONCRETE

\begin{tabular}{|c|c|c|c|c|c|c|c|c|c|c|}
\hline No. & $\begin{array}{l}\text { Cementin } \\
\text { g material }\end{array}$ & Cement & I FA & $\begin{array}{c}\text { fly ash } \\
\text { microsphere }\end{array}$ & S95 & $\begin{array}{c}\text { BM- } \\
\text { HCSA }\end{array}$ & Sand & $\begin{array}{c}\text { coarse } \\
\text { aggregat } \\
\mathrm{e}\end{array}$ & $\mathrm{W} / \mathrm{C}$ & $\mathrm{PC} / \%$ \\
\hline $\begin{array}{c}\text { HCS60 } \\
-0\end{array}$ & 560 & 330 & 90 & 56 & 84 & - & 745 & 949 & 0.27 & 2.2 \\
\hline $\begin{array}{c}\text { HCS60 } \\
-1\end{array}$ & 560 & 308 & 90 & 56 & 84 & 22 & 745 & 949 & 0.27 & 2.1 \\
\hline $\begin{array}{c}\text { HCS60 } \\
-2\end{array}$ & 560 & 296 & 90 & 56 & 84 & 34 & 745 & 949 & 0.27 & 2.1 \\
\hline $\begin{array}{c}\text { HCS60 } \\
-3\end{array}$ & 560 & 285 & 90 & 56 & 84 & 45 & 745 & 949 & 0.27 & 2.3 \\
\hline $\begin{array}{c}\mathrm{HCS} 60 \\
-4\end{array}$ & 560 & 274 & 90 & 56 & 84 & 56 & 745 & 949 & 0.27 & 2.4 \\
\hline $\begin{array}{c}\text { HCS60 } \\
-5\end{array}$ & 560 & 263 & 90 & 56 & 84 & 67 & 745 & 949 & 0.27 & 2.7 \\
\hline
\end{tabular}

The testing result of working performance and strength of concrete is shown in Table 4

TABLE 4 THE TESTING RESULT OF WORKING PERFORMANCE AND STRENGTH

\begin{tabular}{|c|c|c|c|c|c|c|c|}
\hline \multirow{2}{*}{ No. } & \multirow{2}{*}{$\begin{array}{l}\text { collapsed } \\
\text { slump } \\
\text { /flow } / \mathrm{mm}\end{array}$} & \multirow{2}{*}{$\begin{array}{c}\text { Inverted } \\
\text { slump cone } \\
/ \mathrm{s}\end{array}$} & \multirow{2}{*}{$\begin{array}{c}\text { U-box } \\
\text { /mm }\end{array}$} & \multicolumn{4}{|c|}{ Strength $/ \mathrm{MPa}$} \\
\hline & & & & $3 d$ & $7 \mathrm{~d}$ & $14 \mathrm{~d}$ & $28 \mathrm{~d}$ \\
\hline HCS60-0 & $250 / 650$ & 3.2 & 325 & 42.7 & 55.2 & 65.3 & 72.2 \\
\hline HCS60-1 & $255 / 660$ & 3.4 & 330 & 40.2 & 52.8 & 60.5 & 71.6 \\
\hline HCS60-2 & $255 / 660$ & 3.5 & 331 & 41.5 & 54.1 & 64.9 & 72.6 \\
\hline HCS60-3 & $250 / 645$ & 3.8 & 328 & 38.5 & 49.15 & 60.2 & 68.8 \\
\hline HCS60-4 & $245 / 630$ & 4.5 & 325 & 37.6 & 50.4 & 58.8 & 65.4 \\
\hline HCS60-5 & $240 / 600$ & 5.3 & 320 & 35.2 & 43.3 & 50.6 & 61.5 \\
\hline
\end{tabular}

As shown in Table 4, increasingly added with expanders has a certain impact on the working performance of concrete. When mixed with excessive expanders, not only the fluidity, workability and cohesiveness have been affected, but also have some adverse effect on the strength of concrete. References show that, expanders will absorb certain admixtures and water, which will cause reduced working performance and increased cohesiveness, thus the content of expanders should not be too much from the considerations of concrete working performance.

It also can been seen from Table 4, with the increase of expanders, the strength of concrete has some decrease, but still have reached 60Mpa. Expansion properties of concrete have certain relevance with concrete strength. When dosage of expanders is lower, produced micro-expansion can make dense concrete structure, result in concrete strength increase. When dosage of expanders is higher, greater expansion of concrete may result in an increase of internal defects in concrete structure, thus decreased the strength. Expanders should be in the right amount, to meet the coordinated development of strength, working performance and expansion. 
Expansion Properties of Concrete. With the increase of expanders, the free expansion rate of concrete increases as seen in Figure 4. Expansion reaction started early, and the free expansion reached largest within $7 \mathrm{~d}$, later expansion rate of concrete gradually stabilized until equilibrium. When dosage of expander is $8 \%$, the free expansion of concrete reached $0.04 \% \sim 0.06 \%$, with $10 \%$ content of expander, free expansion reached $0.07 \sim 0.09 \%$, and with $12 \%$ content of expander, free expansion reached $0.07 \sim 0.10 \%$.

Concrete restrained expansion ratio is an important indicator of its expansion performance. It represents the capability that internal tensile stress due to shrinkage can be roughly offset by the pre-stress. The test result of concrete restrained expansion ratio is as shown in Figure 5. When expanders content is greater than $8 \%$, the expansion properties of concrete specimen is obvious in the case of unidirectional restrained. Conversely, it can only compensate shrinkage in the case of unidirectional restrained. For more expansion of concrete, it can not only compensate for non-restraint concrete shrinkage, but also generate stress. The resulting restrained shrinkage generated by stress is gradually increased over time and stabilized like stress, as the restrained steel skeleton is not rigid, make expansion concrete not only compensate for non-restraint and restrained concrete shrinkage, but also show limited expansion of concrete specimens. For smaller expansion of concrete, there is certain restrained concrete shrinkage in the early hydration, but expansion produced in late hydration is insufficient to compensate for non-restraint concrete shrinkage, thus concrete specimens showed shrinkage.

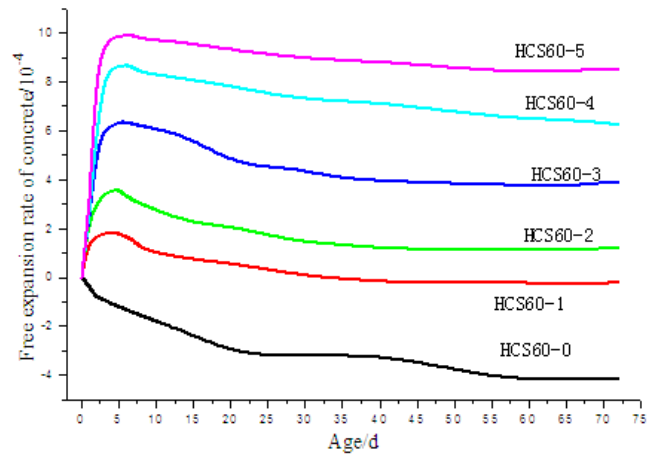

Fig.4 Influence of expanders content on free expansion rate of concrete

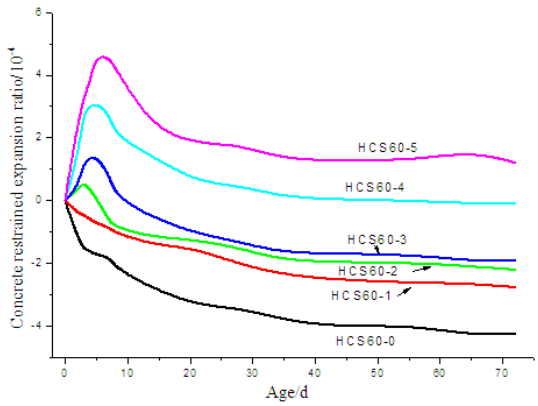

Fig.5 Influence of expanders on concrete restrained expansion ratio

Deformation of expansive concrete in the case of unidirectional restrained $\varepsilon_{2 \mathrm{~m}}$, has following relationship ${ }^{[5]}$ with expansion of concrete $\varepsilon_{1}$, non-restraint concrete shrinkage $S_{t}$ and restrained concrete shrinkage $S_{e}, \varepsilon_{2 m}=\varepsilon_{1}-\left(S_{t}+S_{e}\right)$. In which the restrained shrinkage of concrete results from the stress, thus has corresponding relationship with stress. For concrete with certain expansion, stress can be improved by increasing the stiffness limit, or reducing the limited deformation of restrained concrete.

Influence of Expander on Cement Hydration and Microscopic Analysis. To compare with the XRD patterns of cement specimens mixed with expander and contrast specimens without expander curing for $3 \mathrm{~d}$ and $28 \mathrm{~d}$. Analyze the impact of composite expanders on cement hydration, as seen in Figure 6. 


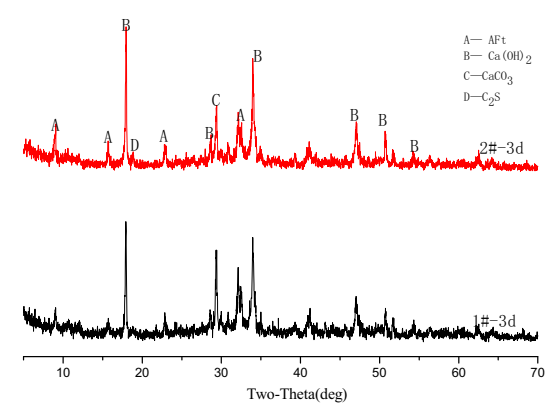

(a) $3 \mathrm{~d}$
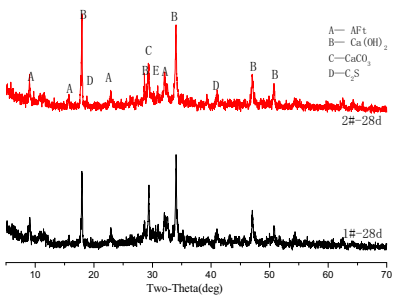

(b) $28 \mathrm{~d}$

Fig. 6 XRD patterns of cement specimens

As seen in Figure in 6, sample 1 \# is contrast specimens without expander, sample 2 \# is cement specimens with $10 \%$ content of expander. After hydration of $3 \mathrm{~d}$, the apparent diffraction peaks of AFt at $2 \theta$ of $9.1^{\circ}$ appeared. The AFt diffraction peak intensity of $2 \#$ is higher than sample $1 \#$, means sample 2 \# produced more AFt, mainly for expansive hydration product. $\mathrm{Ca}(\mathrm{OH})_{2}$ is the main product of cement hydration, with $2 \theta$ of $18.0^{\circ}$ as characteristic diffraction peaks. The $\mathrm{Ca}(\mathrm{OH})_{2}$ diffraction peak intensity of $2 \#$ is higher than sample 1 \# in the early hydration of $3 \mathrm{~d}$, thus, expanders has certain effect in promoting early hydration of cement, which is favorable for the early strength.

As seen in Figure 7, cement hydration specimens curing for $3 \mathrm{~d}$, is more porous and loose in structure, showing lots of needle crystals AFt tufted growth, sample 2 \# also shows hexagonal plates of AFm. With the extension of curing age, cement structure is more compact, in contrast specimens, there are almost no AFt, while in sample 2 \#, AFt can still be seen in the gap and junction, which was produced by expansive hydration of expander, the reason of expansion effect.
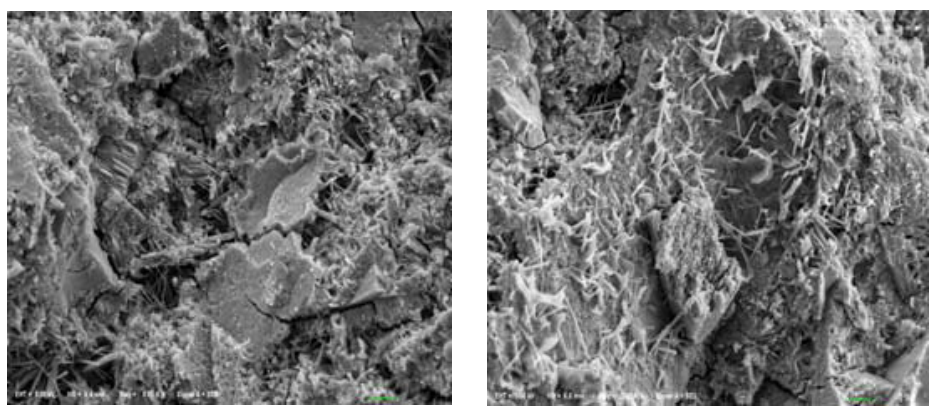


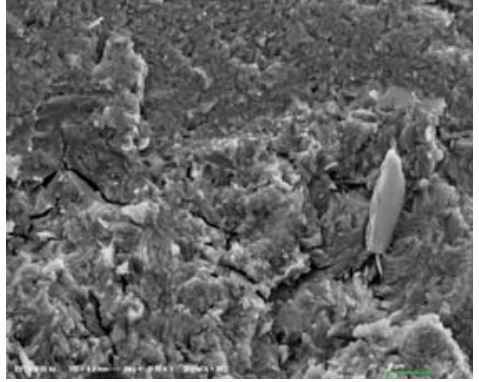

$1 \#-28 d$

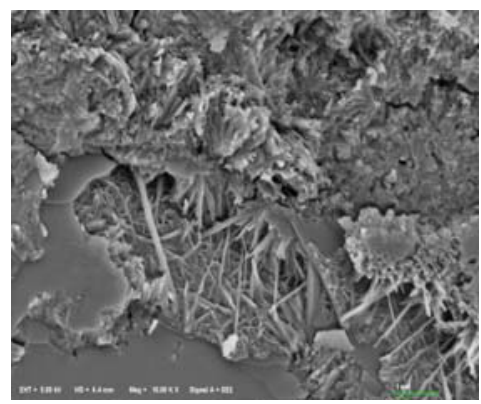

2\#-28d

Fig.7 SEM photograph of cement hydration specimens

\section{Conclusions}

(1) Through the expansion property design and working performance design to prepare C60 concrete filled steel meeting with the self-compacting and expansion properties of core concrete, expander should not be too much, or working performance and strength will be affected.

(2) Free expansion reflects the expansion capacity of expansion concrete, restrained expansion is the expansion deformation offset by the restrained shrinkage and non-restraint concrete shrinkage, there is certain relationship between them. When expander content is $10 \%$, free expansion reached $0.07 \sim 0.09 \%$, restrained expansion ratio reached $0.02 \% \sim 0.03 \%$

(3) Cement specimens with expander has more expansive hydration products of AFt, and produce more hydration product of $\mathrm{Ca}(\mathrm{OH})_{2}$ for $3 \mathrm{~d}$ hydration, has certain effect in promoting early hydration of cement.

This paper was funded by the project Natural science fund of 2015, project number: 51302195.

\section{References}

1. WANG Dongmin, CHEN Huahui, OUYANG Shixi. Investigation on mechanical property and expansion behavior of high strength superplasticized expansive concrete [J] . JOURNAL OF THE CHINESE CERAMIC SOCIETY, 2004, 32(4):454-459

2. QIN Hong-gen, GAO Mei-rong, PANG Chao-ming, SUN Wei. Research on performance improvement of expansive concrete with internal curing agent SAP and its action mechanism [J] . JOURNAL OF BUILDING MATERIALS, 2011, 14(3):394-399

3. WANG Dongmin. Investigation on the composition, structure and performance of high performance expansive concrete (HPEC) [D] . China Building Materials Academy, 2002

4. PU Chun-hong. Study of mixture ratio design and deformation property of high performance expansion steel tube concrete [D] . Chongqing Jiaotong University, 2008201020532900.8, 2011-03-16

5. HU Shu-guang, DING Qing-jun. Steel tube confined concrete [M] . Beijing: China Communications Press, 2007. 